\title{
Síndrome DRESS causado por alopurinol y desencadenado por COVID-19
}

\author{
Allopurinol-induced DRESS syndrome triggered by COVID-19
}

\author{
Telma Elias, Ana Clara Dinis, Cátia Gorgulho \\ Internal Medicine Department. Centro Hospitalar Médio Tejo
}

\begin{abstract}
Drug reaction with eosinophilia and systemic symptoms syndrome (DRESS Syndrome) is caused by many different aetiological factors. We present the case of a 56-year-old woman who started allopurinol treatment about 3 weeks before. She presented with fever, hypotension, tachycardia, generalized maculopapular cutaneous rash, facial edema and axillar, inguinal and cervical enlarged lymph nodes. Complementary diagnostic exams: slight lymphocytosis, eosinophilia, acute renal failure, elevated hepatic enzymes. Swab for SARS-CoV-2 was positive. Serologic tests for another virus were negative. Histopathological analysis was compatible with DRESS syndrome. SARS-CoV-2 could also be taken into account when suspected DRESS syndrome.
\end{abstract}

Keywords: DRESS, eosinophilia, rash, allopurinol, COVID-19

Palabras clave: DRESS, eosinofilia, erupción, alopuinol, COVID-19

\section{INTRODUCTION}

Drug reaction with eosinophilia and systemic symptoms syndrome (DRESS syndrome) or most recently named as drug-induced hypersensitivity syndrome (DIHS) is usually followed by a variety of clinical manifestations, like fever, rash, lymphadenopathy, eosinophilia, and a wide range of mild-to-severe systemic presentations ${ }^{1}$. It is caused by many different aetiological factors, however, to our knowledge, the presentation of a DRESS syndrome secondary to allopurinol intake and triggered by COVID-19 infection is infrequent.

\section{CASE REPORT}

A 56-year-old woman was admitted to the emergency department (ER) due to diarrhea (about 6 daily liquid injections) without blood or mucus, associated with a generalized maculopapular rash, facial edema and fever (ear temperature $38,9^{\circ} \mathrm{C}$ ), with partial response to antipyretics, without predominance of time. She started alopurinol treatment 3 weeks before. On physical examination, she presented fever (ear temperature $38.6^{\circ} \mathrm{C}$ ), hypotension with mean arterial pressure $<65 \mathrm{mmHg}$, tachycardia (127 bpm) and besides a generalized maculopapular cutaneous rash on more than $75 \%$ of her body surface area that did not spare the palms or the feet, accompanied by facial edema and axillar, inguinal and cervical enlarged lymph nodes (Figures 1 and 2).

Among the complementary diagnostic exams performed at admission, there was a slight lymphocytosis $\left(11,3610^{\wedge} \mathrm{g} / \mathrm{L}\right)$, eosinophilia $\left(2,310^{\wedge} \mathrm{g} / \mathrm{L}\right)$, acute kidney injury (serum creatinine $4,3 \mathrm{mg} / \mathrm{dL}$ and blood urea nitrogen $124 \mathrm{pg} / \mathrm{dL}$, estimated glomerular filtration rate (GFR) $14 \mathrm{~mL} / \mathrm{min} / 1,73 \mathrm{~m}^{2}$ ), elevated liver enzymes (AST $956 \mathrm{IU} / \mathrm{L}$, ALT $745 \mathrm{IU} / \mathrm{L}$, lactate dehydrogenase (LDH) $637 \mathrm{IU} / \mathrm{L}$ ) and elevated high sensitivity troponin $(1654 \mathrm{pg} / \mathrm{mL})$. Arterial blood gases showed metabolic acidaemia and hyperlacticaemia. Swab for SARS-
CoV-2 was positive. Serologic tests for herpes virus, cytomegalovirus (CMV), Epstein-Barr virus (EBV), human betaherpesvirus 7 (HHV-7), human immunodeficiency virus (HIV), and hepatitis $B$ and $C$ virus were negative. A skin biopsy was performed, and histopathological analysis showed dermis with polymorphic inflammatory infiltrate and predominantly mononuclear and eosinophilic cells dispersed, perivascular, suggestive of DRESS syndrome. Allopurinol was immediately discontinued, and we started a therapy with intravenous corticosteroids (prednisolone $1 \mathrm{mg} / \mathrm{kg} /$ day). The rash was progressively vanished (after more than 15 days), and the patient experienced a progressive general improvement.

\section{DISCUSSION}

DRESS syndrome is linked to a variety of drugs being the most common allopurinol, anticonvulsants, minocycline, sulfasalazine, disulfone, fluindione, proton pump inhibitors and strontium ranelate. It has a latency period between 2 to 6 weeks. The mortality rate is high (approximately 10\%) ${ }^{1}$.

According to scoring system for classifying DRESS cases (RegiSCAR), that is designed to grade as "no: <2 points", "possible: 2-3 points", "probable: 4-5 points" or "definite: $\geq 6$ points" case of DRESS Syndrome, our patient scored 9 points: fever $\geq 38.5^{\circ} \mathrm{C}(1)$, enlarged lymph nodes (1), eosinophilia (1), atypical lymphocytes (0), skin rash extent $>50 \%$ body surface area (1), skin rash suggesting DRESS (1), biopsy suggesting DRESS (1), organ involvement (2), resolution $\geq 15$ days ( 0 ), viral titers (HBV/HCV) negative (1) (2,3. $^{2}$.

Frequently, clinical presentation is an extensive mucocutaneous rash that is usually followed by fever, and most commonly lymphadenopathy, hepatitis, haematologic abnormalities with eosinophilia and atypical lymphocytes. It involves several organs, being the severity of this syn- 
Figure 1. Generalized erythematous maculopapular rash with desquamation areas (leg).

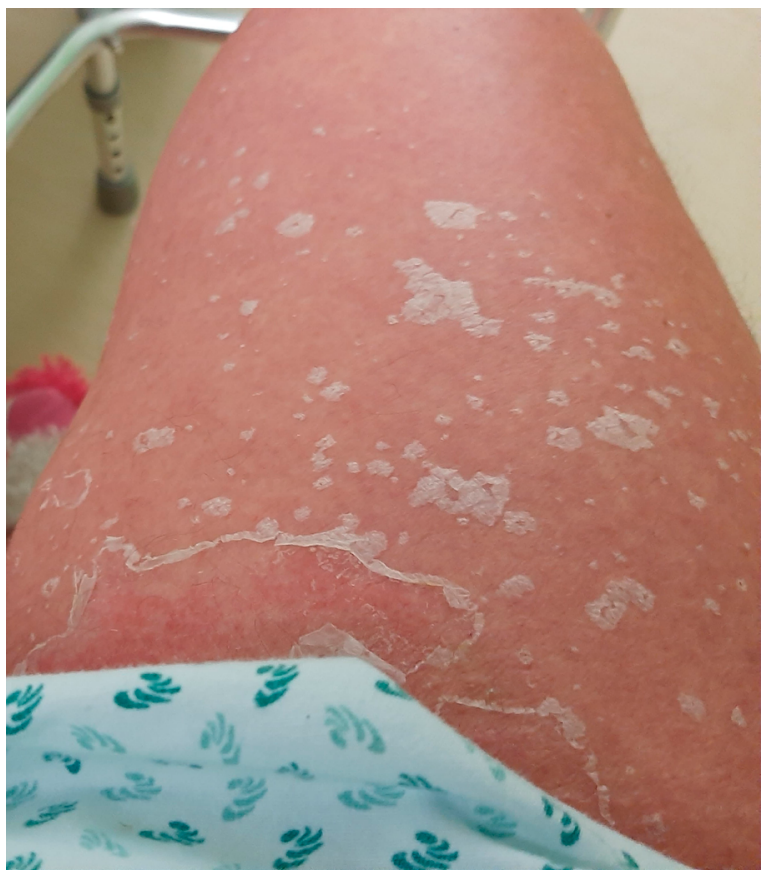

Figure 2. Generalized erythematous maculopapular rash including lips.

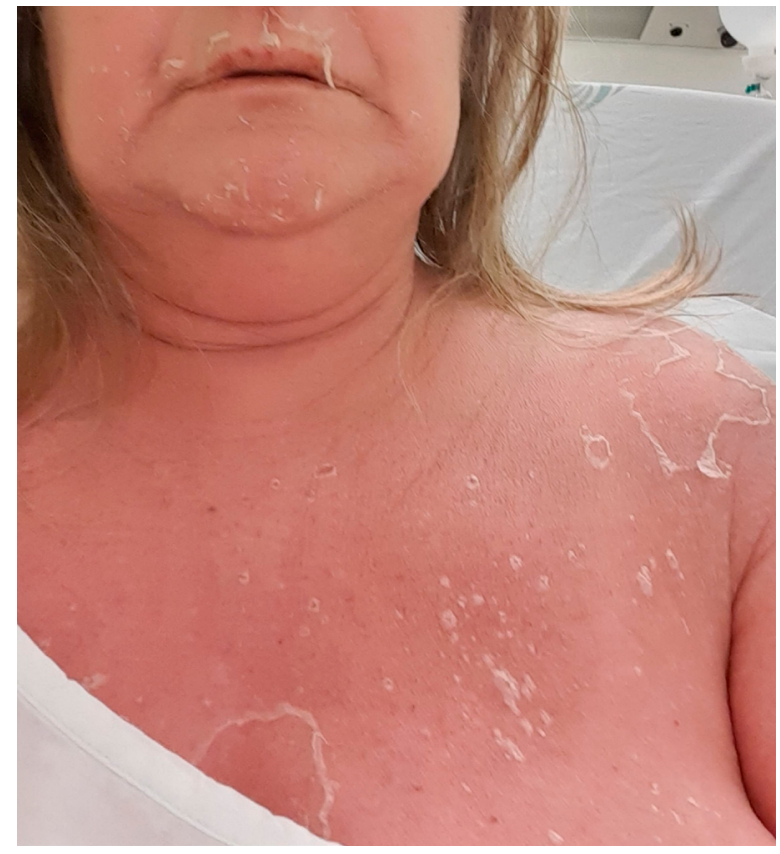

drome related to this systemic involvement that can result in multi-organ failure, most commonly from fulminant hepatitis with hepatic necrosis ${ }^{4}$.

Renal involvement is only present in about $11 \%$ of cases of DRESS syndrome, as was the case of our patient, however the most frequent drug to present renal involvement is allopurinol ${ }^{1}$. Several cutaneous alterations associated with COVID-19 have been described in the literature and, therefore, we must be aware when starting new drugs in this pandemic phase, in order to quickly diagnose this serious entity with high mortality ${ }^{5}$

\section{CONCLUSION}

DRESS syndrome is a complex disease, with usual involvement of multiple organs and associated with a variety of drug interactions, viruses and immune response. SARS-CoV-2 can be a new virus to take into account when DRESS syndrome is suspected.

\section{CONFLICTO DE INTERESES Y FUENTES DE FINANCIACIÓN}

The authors declare that there is no conflict of interest in this work.

Financiación: The authors declare that there were no external sources of study for the performance of this article.

Aspectos éticos: The authors declare that no data that allows identification of the patient appears in this article.

\section{REFERENCIAS}

1. Abhishek De, Murlidhar Rajagopalan,Aarti Sarda, Sudip Das and PB. Drug Reaction with Eosinophilia and Systemic Symptoms: An Update and Review of Recent Literature. Indian J Dermatol. 2018;63(1):30-40.

2. S.H. Kardaun, A. Sidoroff, L Valeyrie-Allanore, S. Halevy, B.B. Davidovici, M. Mockenhaupt JCR. Variability in the clinical pattern of cutaneous side-effects of drugs with systemic symptoms: does a DRESS syndrome really exist? Br J Dermatol. 2007;156(3609-611).

3. Bocquet H, Bagot M, Roujeau JC. Drug-induced pseudolymphoma and drug hypersensitivity syndrome (Drug Rash with Eosinophilia and Systemic Symptoms: DRESS). Semin Cutan Med Surg. 1996 Dec;15(4):250-7.

4. Cho YT, Yang CW, Chu CY. Drug reaction with eosinophilia and systemic symptoms (DRESS): An interplay among drugs, viruses, and immune system. Int J Mol Sci. 2017;18(6).

5. Sachdeva M, Gianotti R, Shah M, Bradanini L, Tosi D, Veraldi S, et al. Cutaneous manifestations of COVID-19: Report of three cases and a review of literature. J Dermatol Sci [nternet]. 2020;98(2):75-81. Available from: https://doi. org/10.1016/j.jdermsci.2020.04.011 